\title{
Leveraging Enterprise Mobility Innovation for Knowledge Sharing in the Airline Industry with Implications for Engineering Education
}

\author{
Dr. Douglas M. Schutz, Tokyo University of Science
}

Douglas M. Schutz is an Associate Professor of Information Systems, International Business, and Management at the Tokyo University of Science in Japan. He received a Ph.D. in Business Administration focusing on Management Information Systems (MIS) from the Fox School of Business of Temple University at Philadelphia, an MBA in Information Management from the McCombs School of Business of the University of Texas at Austin, and a B.S. in Electrical Engineering from the United States Naval Academy at Annapolis focusing on digital design. Doug was one of $40 \mathrm{Ph}$.D. students selected globally to present his research at the International Conference on Information Systems (ICIS) Doctoral Consortium in Shanghai, China. His research has been nominated Best Paper at the Hawaii International Conference on Systems Science (HICSS), and his work has been published three times in publications of the Japan Society of Information and Management (JSIM). Prior to academia, Doug worked as an IT manager and consultant in the electric utility industry out of New Orleans for two Fortune 500 companies, where his responsibilities included IT disaster recovery from Hurricane Katrina. Previously, he served as an unrestricted line officer in the U.S. Navy onboard a guided missile destroyer and the second Aegis cruiser.

\section{Prof. Dante Dionne, Korean Air}

Dante Dionne is an Organizational Leadership PhD candidate and a Senior Innovation Technology Manager at Korean Air. The past 20+ years of his career has centered on management and professional services consulting. Where, he has specialized in leading multi-national project teams in the design and implementation of digital marketing, mobility and innovative technology solutions.

Dante holds an MA in Industrial/Organizational Psychology from the Chicago School of Professional Psychology and a BS in Business Management with a minor in Computer Science. Dante is an adjunct faculty member at the Chicago School of Professional Psychology with Graduate level teaching credits in Psychometrics, Data Management and as a Visiting Scholar at the University of Science in Tokyo. Dante's dissertation research spans several specializations in psychology including: Organizational, Social, Cultural, Developmental, Cognitive, Performance, Sports, and Positive Psychology. Dante is also an active member of American Psychological Association (APA) Division 46 (Society for Media Psychology and Technology), Division 14 (Society for Industrial and Organizational Psychology), Division 13 (Society of Consulting Psychology) and Division 47 (Society for Sport, Exercise and Performance Psychology).

\section{Prof. Yong-Young Kim, Konkuk University}

Yong-Young Kim is assistant professor of Division of Business Administration and Economics at Konkuk University in Korea. He earned his Master's and Doctoral Degree in Management Information Systems from Seoul National University in Korea. His research interests include Smart Work, online games, IT experiential learning processes, IT convergence \& platform, and ubiquitous computing. His papers have appeared in Information Resources Management Journal, Cluster Computing, International Journal of Advanced Media and Communication, Asia Pacific Journal of Information Systems, and Journal of Korean OR/MS Society and also have been presented at many leading international conferences (ICIS, HICSS, PACIS). 


\title{
Leveraging Enterprise Mobility Innovation for Knowledge Sharing in the Airline Industry with Implications for Engineering Education
}

\begin{abstract}
Advances in engineering have led to the continued miniaturization and increased computing power and capabilities of mobile computing technologies. These technical advances get their ultimate start from engineering education that cultivates young people for technical careers of design and development for the Information Age. Engineering education is, therefore, benefiting industry by educating engineers who continue to advance such innovations as mobile computing smartphones. In this paper, we argue that industry can conversely benefit engineering education in how technology is applied for sharing knowledge within and beyond the boundaries of the organization. The airline industry in particular is an area that demonstrates how knowledge sharing experiences can be enabled through the use of mobile computing innovations in the field. Global competition requires firms to rapidly and effectively develop and share knowledge. Knowledge and learning enabled through the use of advanced technologies are, therefore, among the most critical organizational assets for achieving and maintaining competitive advantage.

Drawing from the literature streams of knowledge sharing, social learning theory, and IT mobility, this interpretive case study introduces a theoretical two by two framework. This framework serves as our lens for assessing how migrating from using legacy to advanced technologies can motivate and enable learning. Through observations, questionnaires, and interviews, we test the framework in a case study evaluating the benefits gained from the implementation of smartphones replacing walkie-talkies at a global airline. Through our framework, we identify new opportunities and challenges in sharing and learning knowledge via smartphones. We then argue that similar benefits can be gained for engineering education delivery at universities, drawing from social learning theory and a student-centered learning educational pedagogy. Hence, this research is applicable to not only the airline industry, but also to engineering education for greater understanding and leveraging of knowledge sharing through mobile computing.
\end{abstract}




\section{Introduction}

Airline workers are switching from using two-way radios to smartphones for their enhanced capabilities for sharing and learning knowledge as a platform across time and space.

Collective knowledge and the ability to know represent the intellectual capital of a firm. These mobile capabilities become more enhanced as well as less expensive over time and are, therefore, become more accessible. In this paper we develop a theoretical framework which we test through a case study on a large global airline at a major international airport. The site selected was a regional airport operations department for a prominent global airline situated at a large North American airport. This particular setting is one of the largest regional airport operations outside of the selected airline's primary country of origin in Eastern Asia. To maintain anonymity of research participants, the pseudonym "FlyAsia" will be used for the organization in this study.

The benefits of using this framework are illustrated through a pilot study implementation of smart phones that are replacing legacy walkie-talkies. Data is collected and triangulated by observations, questionnaires, and interviews. This case study is analyzed through the framework, revealing how mobile services can be leveraged and improved for sharing knowledge between the organization and its employees. The phenomenon of leveraging smartphone functionalities in a real-world organizational context are analyzed. As such, a descriptive linear-analytic interpretive case study research design was selected and employed [1]. The framework can also be applied to assessing the sharing of knowledge in a classroom between students and professors using mobile computing devices such as smartphones. This can be particularly helpful at engineering schools where classes are being turned "upsidedown" with peer-led team learning workshops. This active-learning approach has led to increased confidence, intellectual curiosity, and interest in teaching among students [2].

Airlines that implement advanced mobile computing platforms such as smartphones are empowering their employees to collectively share knowledge for solving problems faster, with innovative solutions to better inform and serve their customers. Hence, airline organizations are replacing their legacy walkie-talkie radio communication systems with smartphones loaded with mobile apps for not only seeking, but also for sharing knowledge. This leads to our research question: How can engineering education benefit from understanding how mobile computing innovation is used for enhanced knowledge sharing in the the airline industry?

We next present a literature review of knowledge sharing and social learning theory. We then present our theoretical framework. This is followed by the case study in the airline industry. The paper concludes with implications for engineering education as well as recommendations for future research.

\section{Knowledge Sharing and Social Learning Theory}

Active learning can be accomplished through creating, sharing, and reading knowledge using smartphone affordances between employees, customers, and between employees and customers. This same type of learning can also be enabled using web-based media between students and instructors inside or beyond the classroom [3]. Seekers of content are learning from the posting activity of others, and will likely share by posting their own contributions [4]. Drawing from Hansen and Haas [5], the smartphone is viewed as an internal knowledge platform for the organization where seekers and sharers respectively have simultaneous 
incentives in providing demand and supply of knowledge between one another. Examples of using smartphones for seeking knowledge include using apps for searching, reading, listening, watching, and taking pictures as well as videos. Examples of sharing knowledge include using apps for posting, commenting, texting, typing, attaching, and speaking. Knowledge is both an input and an outcome of the continuous and simultaneous actions which can be enacted by using smartphone functionalities for seeking and sharing knowledge with others. Measuring the usage of the smartphone multi-dimensional uses for seeking and sharing knowledge can even capture how knowledge sharing is actually influenced and enacted.

Nonaka [6] describes the two dimensions of knowledge as being either explicit or tacit. Explicit knowledge is codified and captured in archives and databases in discrete words or numbers. Tacit knowledge, on the other hand, provides the context for developing and understanding explicit knowledge [7]. Tacit knowledge is not codified and is, therefore, harder to communicate. The development of tacit knowledge is a continuous activity between individuals sharing experiences for mutual understanding [6].

Knowledge needs to be continuously created in order for it to be continuously shared. Nonaka [6] proposes that knowledge is created through the conversion between tacit and explicit knowledge via four modes, referred to by the acronym SECI, in a continuous cycle: 1) socialization $(S)$ is creating tacit knowledge from other tacit knowledge through shared experiences; 2) externalization (E) is converting tacit knowledge into explicit knowledge through codification; 3 ) combination $(C)$ is creating explicit knowledge from other explicit knowledge by sorting, adding, and categorizing from exchanges with others; 4) internalization (I) is the converting of explicit knowledge into tacit knowledge for individual learning.

Knowledge can be viewed as an object in the sense that it can be gathered, stored, and transferred like an "object" [7]. Knowledge can also be viewed as a process in that it can be developed, shared, and distributed. Through the lens of practice, the understanding of knowledge extends beyond development or delivery, and can include the consumption and shared participation by employees and groups alike within the organization [8].

The ongoing seeking and sharing of knowledge between consumers and producers of content via smartphone platforms supports the notion of the continuous conversions of tacit and explicit knowledge through practice [6]. Through practice, enabled by using the functionalities of smartphones, knowledge as an object and as a process is developed, shared, viewed, and consumed which, in turn, can lead to the development of new knowledge by interacting with others connected through the platform.

Choi, Lee [9]) show that IT systems consisting of knowledge repositories, search engines, and interactive bulletin boards can have a positive impact through practice on learning through knowledge seeking and sharing for resolving new problems. From organizational theory, the creation of knowledge can positively impact organizational performance in such areas as innovation, product development, and competitive advantage [6]. The same is true for universities, particularly schools of engineering where concepts continuously advance. As an object and through practice, IT-enabled knowledge sharing can support such activities as combining of new sources of knowledge, inter-group access of stored knowledge, internal knowledge transfers, and the efficient application of new knowledge through workflow automation for multiple locations [7]. 
Knowledge is information that has been personalized through meaningful relations which can be useful $[5,7]$. Knowledge is created by combining elements that are previously unconnected, or by creating new ways for combining previously connected elements [10]. Hence, intellectual capital is cultivated in the firm by combining knowledge in new ways from different stakeholders of varying expertise and experiences [11]. Seekers and sharers of a knowledge platform exchange and recombine elements of knowledge with one another [5]. The use of the functionalities of the corporate smartphone platform serves as the intermediary for enabling the creation, combination, and sharing of knowledge for the intellectual capital of the firm. In this paper we view that the same can be applied for the intellectual capital of engineering students in the classroom.

Knowledge sharing can have a direct impact on knowledge application, which, in turn, can positively influence team performance. However, knowledge sharing may not have a direct influence on team performance if it is not effectively applied in practice [9]. Knowledge is emergent, and communicating tacit viewpoints is, therefore, an important factor in the creation of knowledge that can be effectively applied [7, 12]. As an object, knowledge can be useable, and in practice, knowledge can be made useful and shared so that it can be effectively used. If knowledge does not evolve and remains just as the same object, it may be useable, but not very useful for long. Alternatively, if knowledge was just enhanced through practice, it may be useful, but this would not matter if no one could use it.

Knowledge is a critical asset in an organization that needs to be efficiently collected and archived so that users through the corporate smartphone platform are able to seek knowledge as an object. At the same time, knowledge needs to be developed, updated, and shared through practice so that users are sharing knowledge that is useful and used by seekers in their work. Organizations need employees to share knowledge with one another. Similarly, universities need professors and students alike to share and absorb each others knowledge in the classroom. Employees as well as students who do not frequently draw from others in similar situations run the risk of path dependency from the reinforcement of their own learning-by-doing [13-15].

In sum, knowledge sharing through smartphone-enabled services needs proactive monitoring not only for sharing, but also for seeking, so that both of these activities are balanced. Management as well as faculty should look for ways to keep seeker search costs low. For example, seekers can benefit by providing the identification of the sources of knowledge and allowing for the manipulating of posted knowledge so that it can be effectively applied to particular situations [16]. Incentives such as personal recognition can be used to encourage knowledge sharing [14]. However, while a larger number of knowledge contributors can be beneficial, the quality of the knowledge that is shared is more beneficial than the quantity [5, 17].

User-generated content, a key attribute of social media apps, can provide not only useful knowledge for solving problems, but also helpful feedback on the solutions that are shared, and on the sharers themselves [14]. This can be managed through ratings of posted comments based on the usefulness of the solutions from the seekers who have actually learned and applied the shared knowledge for their work [14]. Hence, both seeking and sharing knowledge can be managed for balance as well as for ongoing opportunities for the employees in the organization, as well students in engineering schools. 
Firms may delay their adoption of new technologies until they gain sufficient in-house expertise through organizational learning or skills development, or hire the technical knowhow from outside the company to lower the knowledge barriers [18]. The implementation of new IT artifacts in organizations requires employees to not only learn how to use the material features, but to also learn how the new technologies manage knowledge [19]. We next show how social influence can be such a key factor for learning through the use of smartphone platforms for seeking and sharing knowledge between users, be they employees or students.

Spatial networks based on geographic distribution can influence IT diffusion through the observation of others [20]. Through observation, a user's beliefs and evaluations, based on the relative advantage and ease of use in using an IT innovation, can have a positive influence on attitude for adopting the new technology [21]. Informational influence also draws from the theory of social learning in that the individual learns how to use new systems from the experience of others, thus avoiding the opportunity costs of trying to learn on his or her own [22].

From social learning theory, human behavior is described as an ongoing interaction among cognitive, behavioral, and environmental factors [22]. One learns how to execute new behaviors by observing others, which enables individuals to model this information for their own subsequent actions [22]. Students learn by observing and mimicking their professors and fellow students. Employees in distributed teams mimic the successful, observed behaviors of others for finding expertise and coordinating knowledge with others [23]. Developing and sharing innovative ideas is mainly a reciprocal, social activity relying on the interactive linking of ideas between individuals and collective knowledge [24]. Learning would take much more effort if it was limited to one's own autonomous actions [22].

From student-centered pedagogy learning theory, learning shifts from top-down to bottomup. Through student-centered learning, the individual student is responsible for setting learning goals, working towards them, monitoring feedback, and making appropriate adjustments [3]. However, there are not always positive results when associating Web-based multimedia technology with student learning due to the complexity of the unstructured Web resulting in too much emphasis on learning the technology and not the content of the course [3]. Technology needs to be an enabler for sharing and obtaining course knowledge and not a constraint, or else it could backfire.

When technology enables more than constrains, research in distributed learning classifies individuals as "active learners" when interacting both with posted content and with other learners [25]. Interacting with posted content is referred to as "interaction with content", while interacting with other learners is classified as "interpersonal interaction" [26, 27]. Individuals that both seek content and share content with others through corporate smartphone functionalities are, therefore, the most active learners. This is in contrast to other social media apps users that just seek information without sharing (e.g. lurkers) and those that just share information without seeking (e.g. spammers). Those that neither seek nor share content are "missing in action" and do not learn or contribute through the platform [25]. This is similar to the dynamics in the classroom. Students that never participate (lurkers), those that participate too much (spammers), and those that skip class altogether ("missing in action"), do not learn or contribute as much as those that have a balance of both listening and participating in classroom discussions. 
Individuals, as well as the organizational platform itself, gain by a balance in both seeking and sharing knowledge, so that the benefits from individual participation exceed the (opportunity and search) costs. Smartphone platform users that resemble "lurkers", "spammers", or are "missing in action" provide opportunities for managers as well as professors to determine why these employees or students are not "active learners", by both seeking and sharing knowledge with others. Neither seekers nor sharers benefit when shared content is not read, or if seekers waste time reading content of no value [28].

The potential added value from the social influence of network externalities of a user base of active participants from the business unit (or classroom) and overall organization (or engineering school) should further motivate users beyond normative and informational social influence. The social influence of the network externalities of others using smartphone platforms for the reciprocal seeking and sharing of knowledge through interpersonal interactions should, therefore, extend beyond unidirectional normative or informational influences. Hence, the social influence from network externalities and critical mass need to be considered in order to fully understand and take into account how and why individuals are motivated from the benefits of using smartphone platforms for exchanging knowledge.

In sum, the interactive nature of the use of functionalities of smartphone platforms in the firm or university for both seeking and sharing is different from the use of traditional, personal productivity IT of the past. Smartphones typically have both universal access as well as reciprocal interdependence $[29,30]$. The social influence of network externalities and critical mass, therefore, provide a mechanism for taking into account the increased potential benefits that "spill over" to new users due to the increased size of the user base using the smartphone platform [31-33].

Users of smartphone platforms in the organization or university for active learning are not just unidirectional consumers, they are also producers of their own content [25,34]. Network externalities and critical mass extend beyond normative and informational social influence that is sequential, focusing on unidimensional use [35-37]. Network externalities and critical mass enable the understanding of social influence that is also reciprocal (i.e. in both directions), between the multiple dimensions of seeking and sharing and vice-versa, which, in turn, can quickly lead to greater benefits among the participants.

We next combine the concepts of knowledge sharing and social learning in developing out theoretical framework.

\section{Theoretical Framework}

We now extend the concepts of knowledge sharing, social influence, and mobility with respect to two dimensions in our Knowledge Seeking \& Sharing 2X2 Matrix for Learning (Fig. 1). This framework enables the classifying of mobility services in the organization. The $\mathrm{X}$-axis of the framework is Level of Knowledge Sharing, and the Y-axis is Level of Connectivity. The horizontal axis is bifurcated into knowledge "Seeking" interactions on the left half and knowledge "Sharing \& Seeking" interactions on the right half. The vertical access represents connectivity within and beyond the boundaries of the organization. By connectivity, we draw from Sørenson (2012) in defining this to be the ability to establish connections. The focus of the communication interaction with the lower half focusing on interactions internal to the organization where the level of connectivity is lower for fewer numbers of users. The upper half focusses on interactions external to the organization where 
the connectivity is higher for larger numbers of users. Through this framework we introduce and describe four different classification quadrants of knowledge sharing between employees as well as customers via mobile computing services. These classifications are: 1)

Intraorganizaional Direction, 2) Customer Service, 3) Intraorganizational Interaction, and 4) Public Interaction.

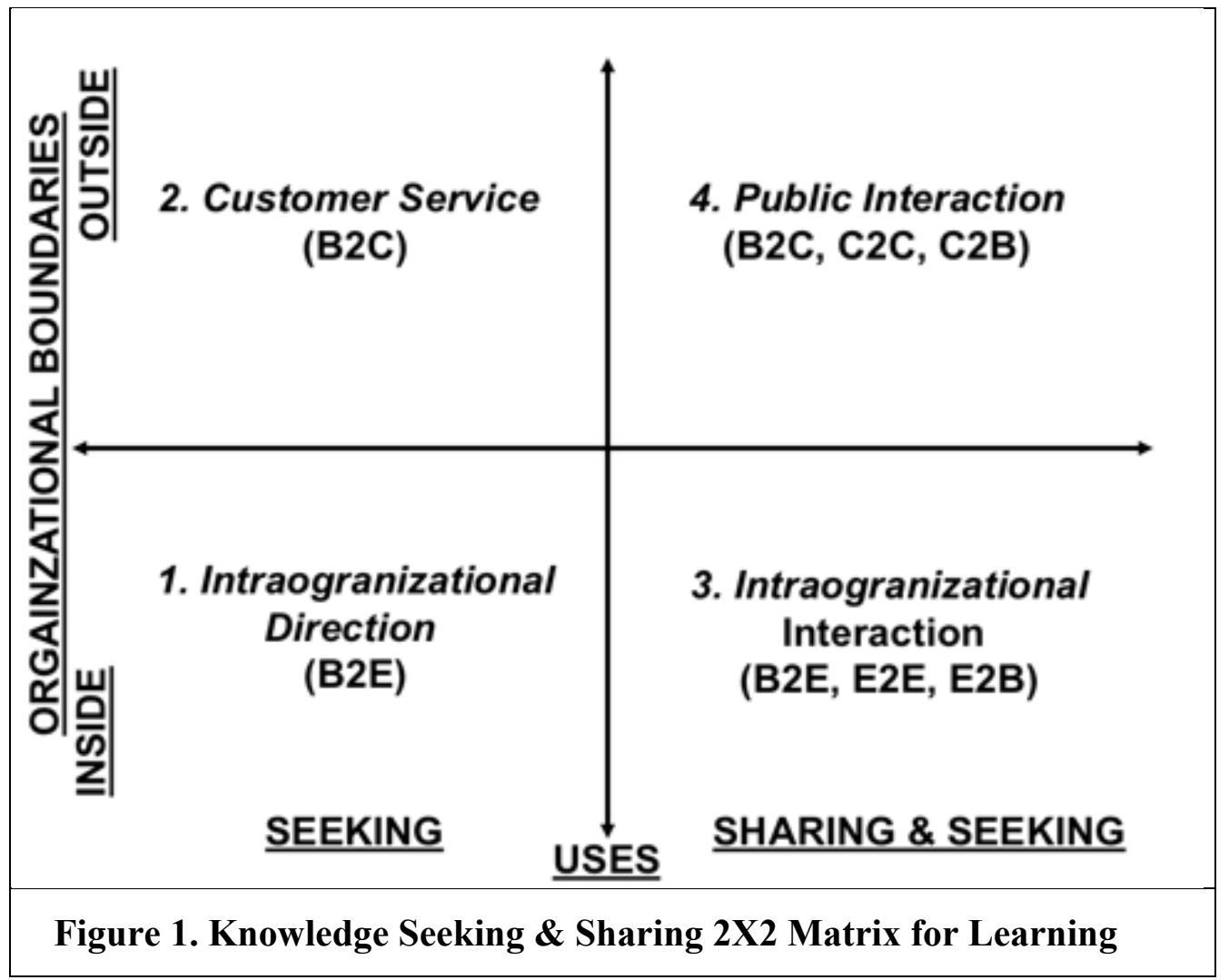

Through the two dimensions, we identify four quadrants for classifying services enabled by enterprise mobility in organizations: 1) Intraorganizational Direction (business to employee or B2E) which has low connectivity and low sharing, 2) Customer Service (business to consumer or B2C) which has high connectivity and low sharing, 3) Intraorganizational Interaction (employee to employee or E2E, business to employee or B2E, employee to business or E2B) which has low connectivity and high sharing, and 4) Public Interaction (business to consumer or B2C, consumer to consumer or C2C, consumer to business C2B) which has high connectivity and high sharing. For 1) Intraorganizational Direction and 2) Customer Service, much of the knowledge sharing can be enabled machine to person by employees or customers viewing codified knowledge. For 3) Intraorganizational Interaction and 4) Public Interaction, knowledge is shared between employees as well as between customers by posting tacit knowledge for viewing and response. Hence, tacit knowledge is converted into codified knowledge. Through the Internet of Things (IoT), knowledge will be shared not only from machine to person and from person to person, but also machine to machine.

We next apply our framework to a global airline company and draw implications for the use of smartphone functionalities for sharing knowledge in engineering education. 


\section{Applying the Knowledge Seeking and Sharing Framework to the Case Study of Learning in the Organization}

FlyAsia (pseudonym), is a large international airline with an established reputation for high quality services. Maintaining a fleet of more than 200 aircraft with an average cost of between \$150-\$350M USD, FlyAsia is well situated among the top 20 global airlines. Operating hundreds of flights per day to hundreds of destinations in dozens of countries, requires a sizeable airline operations staff head count in order to ensure timely aircraft turnaround at each airport it services. Thus, it is a standard practice for airlines to maintain in-house passenger, cargo and aircraft handling personnel in order to ensure the efficient transportation of millions of passengers each year.

FlyAsia plays an integral part in its countries global presence and is a major contributor to the global economy. Yet, operating in the highly competitive international airline industry places constant pressure on airlines to maintain operating profitability. Post 9/11 airport congestion caused by increased security and federalization of passenger screening introduced new challenges for airport operations. In what is now a highly regulated deregulated industry, in order to avoid flight disruptions and flight schedule delays requires increased effectiveness in airport operations team communications. In a departure of its tendency to mimic strategies of other carriers, FlyAsia sought out new efficiencies in its airport communications through technology innovations. An action research study was conducted to assess the efficacy of advanced smartphone based technologies as a potential for enhancing communications and improving passenger flow for its airport operations teams.

Over two dozen airport operations personnel participated in this study that lasted several weeks. Primary airline personnel roles included passenger facing airport operational functions for both inbound (arrivals) and outbound (departures) flights. For example, ticket counter operations, baggage handling functions, gate operations and back office functions. At the beginning of their shifts, personnel were informed by their designated airport operations team leads, that they would be utilizing company provisioned smartphone devices for operational communications in lieu of the regular company provisioned 2-way radio (walkie-talkie) communication devices. The devices were employed over several shifts in order to obtain sufficient activity observation and impression data for analysis and reporting.

Participants were given on-the-spot in-person instruction on the device and PTT application functions. In total, instruction duration lasted 15-30 minutes depending on the level of technology familiarity of participants. Once initial test messages between and among participants were completed, personnel engaged in their normal airport operations functions. This included all passenger facing functions for both inbound (arrivals) and outbound (departures) flights. Over all, two day shifts and two night shifts totaling twenty-two personnel participated in the study.

A typical outbound flight passenger flow entails ticketing, baggage handling services, gate agents and other airport services. All of which work together in tandem to coordinate the incoming aircrafts readiness and loading prior to departure. Similarly, inbound passenger operations flow entails ramp services to disembark incoming passengers, baggage cargo hold to carousel services, passenger transfer management and VIP Services (ex. wheelchair and connection services). 
Data for this case study was collected by questionnaire [38] with open ended comments on impressions and sentiment, observations centered around technology meeting current operational standards, and interviews uncovering unplanned use of technology (ex. using native OS software to check flight on-time status, weather forecasts, etc.). To illustrate our analysis, the theoretical $2 \mathrm{X} 2$ knowledge seeking and sharing framework, a logic model (Fig. 2) was developed for visualizing the resources, activities and results of the implementation approach for functionalities enabled by mobile innovations.

\begin{tabular}{|c|c|c|c|c|c|}
\hline Quadrants & Inputs & Boundary & Outputs & Outcomes & Impact \\
\hline & $\begin{array}{c}\text { How } \\
\text { Resources } \\
\text { are Used }\end{array}$ & $\begin{array}{l}\text { Where } \\
\text { Resources } \\
\text { are Used }\end{array}$ & $\begin{array}{l}\text { Results of } \\
\text { Activities }\end{array}$ & $\begin{array}{l}\text { Changed } \\
\text { Conditions } \\
\text { of } \\
\text { Participant } \\
\text { s }\end{array}$ & $\begin{array}{l}\text { Changes in } \\
\text { Organization, } \\
\text { Community }\end{array}$ \\
\hline 1 & Seeking & Inside & B2E & $\begin{array}{l}\text { Explicit } \\
\text { Knowledge }\end{array}$ & $\begin{array}{l}\text { Employee } \\
\text { Knowledge } \\
\text { Gain }\end{array}$ \\
\hline 2 & Seeking & Outside & $\mathrm{B} 2 \mathrm{C}$ & $\begin{array}{l}\text { Implicit } \\
\text { Knowledge }\end{array}$ & $\begin{array}{l}\text { Customer } \\
\text { Knowledge } \\
\text { Gain }\end{array}$ \\
\hline 3 & $\begin{array}{l}\text { Sharing \& } \\
\text { Seeking }\end{array}$ & Inside & $\begin{array}{l}\text { B2E, E2E, } \\
\text { E2B }\end{array}$ & $\begin{array}{l}\text { Explicit } \\
\text { Knowledge }\end{array}$ & $\begin{array}{l}\text { Employee } \\
\text { Knowledge } \\
\text { Development }\end{array}$ \\
\hline 4 & $\begin{array}{l}\text { Sharing \& } \\
\text { Seeking }\end{array}$ & Outside & $\begin{array}{l}\mathrm{B} 2 \mathrm{C}, \mathrm{C} 2 \mathrm{C} \\
\mathrm{C} 2 \mathrm{~B}\end{array}$ & $\begin{array}{l}\text { Implicit } \\
\text { Knowledge }\end{array}$ & $\begin{array}{l}\text { Customer } \\
\text { Knowledge } \\
\text { Development }\end{array}$ \\
\hline \multicolumn{6}{|c|}{$\begin{array}{l}\text { Figure 2. Activities Approach Logic Model } \\
\text { (Adapted from W. K. Kellogg Foundation, 2004) }\end{array}$} \\
\hline
\end{tabular}

The first scenario (quadrant 1), might be exhibited by firm management and operations team leads ensuring appropriate staff assignments are in place, communicating updates in regulatory information and operations policies. The next scenario (quadrant 2), might be exhibited by airline operations personnel interfacing with arriving and departing passengers. Issuing tickets and boarding pass, checking luggage, and boarding passengers for ensuring timely operations. The next scenario (quadrant 3), might be exhibited by airline operations personnel communications and interaction with each other (the workgroup). For example, coordinating tasks and communicating information to back office operations management. The final scenario (quadrant 4), might be exhibited by airline operations personnel coordinating with vendors such as aircraft cleaning and stocking services. 


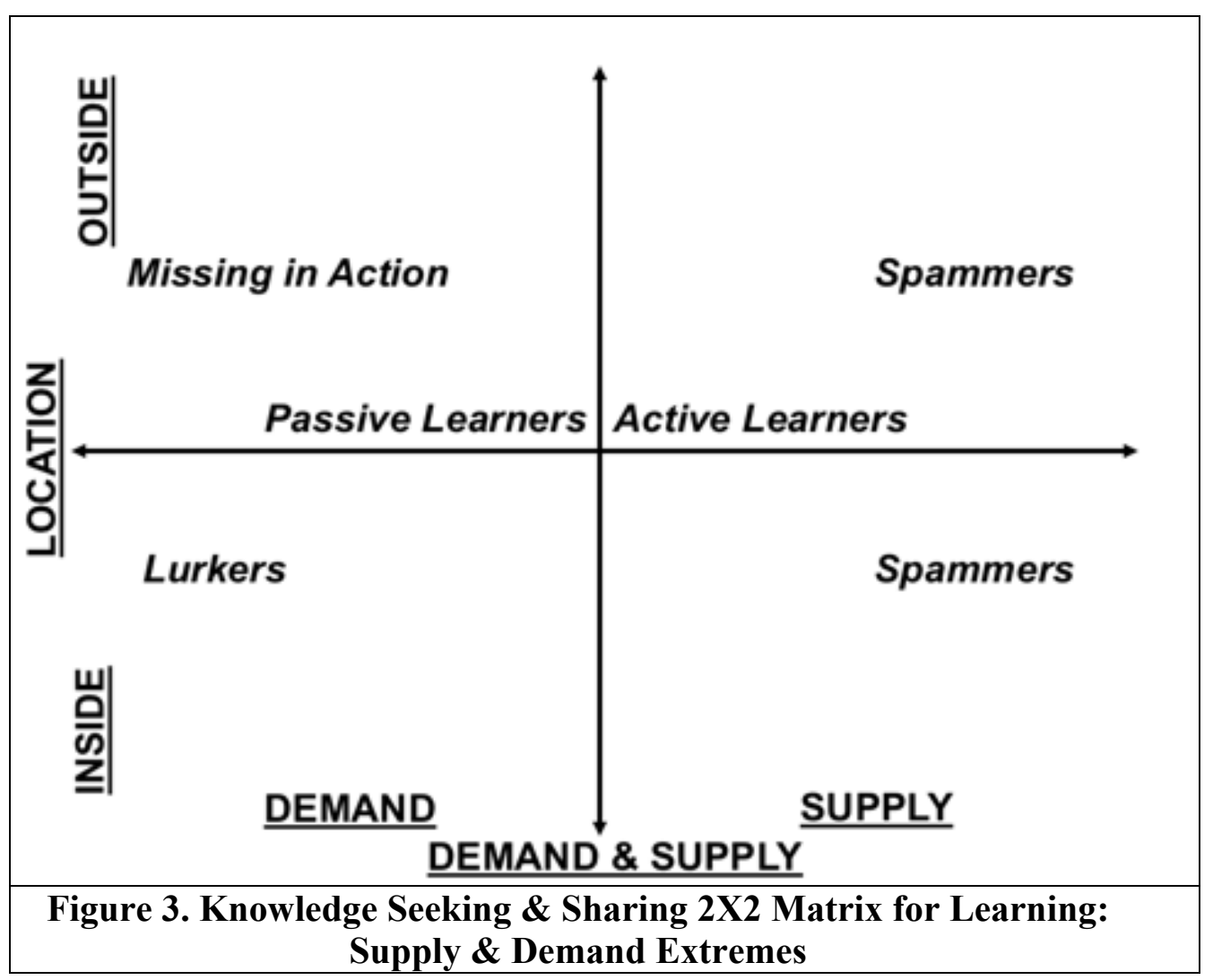

From our previous scenarios, we use Figure 3 to classify learning extremes at FlyAsia. For the left side of the matrix, (quadrant 1), the staff are passive learners where firm management and operations team leads communicate their assignments and policies. If the staff do not interact and just listen, they are lurkers. The next scenario (quadrant 2) also on the left side of the matrix, the passengers are also passive learners as the airline operations personnel interface with arriving and departing passengers. If the passengers do not receive the information, they are missing in action. The final two scenarios demonstrate active learning. For the third scenario (quadrant 3), airline operations personnel interacting with each other and for the final scenario (quadrant 4), airline operations personnel coordinating with vendors such as aircraft cleaning and stocking services. However, for either quadrant on the right side, if there is too much of a supply of information, the suppliers can become spammers.

Future training implications for smartphone based communications include: 1) enabling interactivity and instant access to information across global operations, 2) privacy implications associated with smartphone earpiece, 3 ) locational aware operations via smartphone device geolocation services, 4) multimedia usage (ex. Pictures for misplaced luggage or unaccompanied minors, video messages, etc.), and 5) social media monitoring (ex. Delayed flights, check passenger twitter/Facebook posts for opportunities to ease customer discomfort or enhance customer experience). Engineering education should also benefit from the use of many of these emerging technologies. 


\section{Engineering Education Implications: Pedagogy in Action and Future Research}

This paper shows how the shifting to smartphone platforms enables learning in an airline organization to be more multidimensional through seeking as well as sharing, synchronously or asynchronously. In time critical airport operations, the workgroup is focused on achieving one primary goal - the successful completion of the organizations social contract with arriving or departing passengers [39, 40]. As such, all airline passenger operations personnel are relied upon for their volitional presence in both a pedagogical and leadership capacity. Gomes da Costa [41] used the term "pedagogy of presence" to denote the practice of being a conscientious agent in the social learning and teaching process [41]. In a related concept, "leader presence" may be used to describe the atmospheric command of collective values used to moderate and transform workgroup experiences into mutual learning through the process of knowledge seeking and sharing [42]. In application, each team member communicates and coordinates activities using the smartphone technologies to the entire operations team. This improves the overall workgroup decision making and increasing the capacity to satisfy the obligations and implicit agreement between the business and consumers of services for monies paid [40, 42, 43].

We argue that similar knowledge sharing benefits gained in the airline industry can be gained in engineering schools through the use of smartphone platforms with such collaborative apps as Blogger, LINE, Dropbox, and Google Drive. These Web 2.0 mobile innovations for seeking and sharing knowledge within and beyond the boundaries of the organization are easy to learn by the Millennial Generation, who grew up with computers and the Internet at home. By using the technologies designed and developed by engineers in engineering education will further help recruit, stimulate, and retain students in engineering. Understanding what engineers do with science and technology for helping humanity should help increase the numbers of young people into engineering especially women [44]

Finally, while following the need to maintaining individual privacy requirements, engineering education can benefit in future research by measuring how smartphones are used by professors and students for seeking and sharing knowledge inside and outside of the classroom. Measuring the usage of the smartphone multi-dimensional uses for seeking (e.g. searching, reading, listening, watching, and taking pictures as well as videos) and sharing (e.g. posting, commenting, texting, typing, attaching, and speaking) knowledge would show how knowledge is produced and consumed. By categorizing this usage between seeking and sharing, one can assess at the individual, class, and school-level the status between active and passive learning. Furthermore, anonymous feedback could be provided to students as well as professors so they could check and adjust for more effective learning and/or teaching. 


\section{References}

1. Yin, R.K., Case Study Research: Design and Methods. 2013: Sage Publications.

2. Johnson, E.C., B.A. Robbins, and M.C. Loui, What Do Students Experience as Peer Leaders of Learning Teams? Advances in Engineering Education, 2015. 4(4).

3. Hannafin, M.J. and H.K. M., Cognition and Student-Centered, Web-Based Learning: Issues and Implications for Research and Theory, in Learning and Instruction in the Digital Age, J.M. Spector, Editor. 2009, Springer: New York. p. pp 11-23.

4. $\quad$ Faraj, S., S.L. Jarvenpaa, and A. Majchrzak, Knowledge collaboration in online communities. Organization Science, 2011. 22(5): p. 1224-1239.

5. Hansen, M.T. and M.R. Haas, Competing for Attention in Knowledge Markets: Electronic Document Dissemination in a Management Consulting Company. Administrative Science Quarterly, 2001: p. 128.

6. Nonaka, I., A Dynamic Theory of Organizational Knowledge Creation. Organization Science, 1994. 5(1): p. 14-37.

7. Alavi, M. and D.E. Leidner, Knowledge Management and Knowledge Management Systems: Conceptual Foundations and Research Issues. MIS Quarterly, 2001. 25(1): p. 107-136.

8. Brown, J.S. and P. Duguid, Knowledge and Organization: A Social-practice Perspective. Organization Science, 2001. 12(2): p. 198-213.

9. Choi, S.Y., H. Lee, and Y. Yoo, The impact of information technology and transactive memory systems on knowledge sharing, application, and team performance: A field study. Management Information Systems Quarterly, 2010. 34(4): p. 855-870.

10. Moran, P. and S. Ghoshal, Value Creation by Firms, in Academy of Management Best Paper Proceedings, Dosier, Editor. 1996, In J, B, Keys\& L. N.: Georgia Southern University.

11. Nahapiet, J. and S. Ghoshal. Social Capital, Intellectual Capital and the Creation of Value in Firms. 1997. Academy of Management.

12. Orlikowski, W.J., Knowing in Practice: Enacting a Collective Capability in Distributed Organizing. Organization Science, 2002. 13(3): p. 249-273.

13. Yoo, Y., K. Lyytinen, and D. Heo, Closing the gap: towards a process model of post merger knowledge sharing. Information Systems Journal, 2007. 17(4): p. 321-347.

14. Garud, R. and A. Kumaraswamy, Vicious and Virtuous Circles in the Management of Knowledge: The Case of Infosys Technologies. MIS Quarterly, 2005. 29(1): p. 9-33.

15. Levinthal, D.A. and J.G. March, The Myopia of Learning. Strategic Management Journal, 1993. 14(S2): p. 95-112.

16. Faniel, I.M. and A. Majchrzak, Innovating by Accessing Knowledge Across Departments. Decision Support Systems, 2007. 43(4): p. 1684-1691.

17. Jones, Q., G. Ravid, and S. Rafaeli, Information overload and the message dynamics of online interaction spaces: A theoretical model and empirical exploration. Information systems research, 2004. 15(2): p. 194-210.

18. Attewell, P., Technology Diffusion and Organizational Learning: The Case of Business Computing. Organization Science, 1992. 3(1): p. 1-19.

19. Leonardi, P.M., Activating the Informational Capabilities of Information Technology for Organizational Change. Organization Science, 2007. 18(5): p. 813-831.

20. Rogers, E.M., Diffusion of Innovations. 1983, New York: Free Press.

21. Karahanna, E., D.W. Straub, and N.L. Chervany, Information technology adoption across time: a cross-sectional comparison of pre-adoption and post-adoption beliefs. MIS Quarterly, 1999: p. 183213.

22. Bandura, A., Social Learning Theory. 1977, New York: General Learning Press.

23. Kanawattanachai, P. and Y. Yoo, The Impact of Knowledge Coordination on Virtual Team Performance Over Time. MIS Quarterly, 2007. 31(4): p. 783-808.

24. Bento, J., Jose Duarte, Manuel V. Heitor, William Mitchell, Collaborative Design and Learning: Competence Building for Innovation (International Series on Technology Policy and Innovation). 2004, Westport, Connecticut: Praeger. 409.

25. Bento, R., et al., A taxonomy of participation in online courses. Journal of College Teaching \& Learning (TLC), 2011. 2(12).

26. Moore, M.G., Editorial: Three Types of Interaction. The American Journal of Distance Education, 1989. 3(2): p. 1-6.

27. Berge, Z.L., Conceptual Frameworks in Distance Training and Education, in Distance Training: How Innovative Organizations are Using Technology to Maximize Learning and Meet Business Objectives, D.S.a.Z.L. Berge, Editor. 1998, Jossey-Bass: San Francisco. p. 19-36. 
28. Kraut, R.E., et al., Pricing Electronic Mail to Solve the Problem of Spam. Human-Computer Interaction, 2005. 20(1): p. 195-223.

29. Markus, M.L., Toward a 'Critical Mass' Theory of Interactive Media. Communication Research, 1987. 14(5): p. 491.

30. Ransbotham, S., G.C. Kane, and N.H. Lurie, Network Characteristics and the Value of Collaborative User-Generated Content. Marketing Science, 2012. 31(3): p. 387-405.

31. Lou, H., W. Luo, and D. Strong, Perceived critical mass effect on groupware acceptance. European Journal of Information Systems, 2000. 9(2): p. 91-103.

32. Kraut, R.E., et al., Varieties of social influence: The role of utility and norms in the success of a new communication medium. Organization Science, 1998: p. 437-453.

33. Katz, M.L. and C. Shapiro, Network externalities, competition, and compatibility. The American economic review, 1985. 75(3): p. 424-440.

34. Agichtein, E., et al. Finding high-quality content in social media. in WSDM '08 Proceedings of the international conference on Web search and web data mining. 2008. Palo Alto, CA: ACM.

35. Deutsch, M. and H.B. Gerard, A study of normative and informational social influences upon individual judgment. The journal of abnormal and social psychology, 1955. 51(3): p. 629.

36. Liang, H., et al., Assimilation of enterprise systems: The effect of institutional pressures and the mediating role of top management. MIS Quarterly, 2007. 31(1): p. 59-87.

37. Liang, H. and Y. Xue, AVOIDANCE OF INFORMATION TECHNOLOGY THREATS: A THEORETICAL PERSPECTIVE. MIS Quarterly, 2009. 33(1): p. 71-90.

38. Dionne, D. and D.M. Schutz. Distributed Collaboration of Working Groups in Global Airline Operations: Leveraging Smartphone Push-To-Talk Functionalities. in 10th Annual IEEE IT Professional Conference, The College of New Jersey. 2015. Computer Society Chapter of Princeton and the Princeton Chapter of the ACM (Association for Computing Machinery): IEEE (Institute of Electrical and Electronics Engineers)

39. Cohn, A., et al., Analysis of the Potential for Delay Propagation in Passenger Airline Networks. 2007.

40. Fernando, A.C., Business ethics and corporate governance. 2010: Pearson Education India.

41. Gomes Da Costa, A.C., Por uma pedagogia da presenca [For a pedagogy of presence]. Brasilia: Fundacao Centro Brasileiro para a Infacia e Adolescéncia (FCBIA). 1991.

42. Oliveira, W.D., S.R. Edginton, and C.R. Edginton, Leader presence. Journal of Physical Education, Recreation \& Dance, 1996. 67(1): p. 38-40.

43. Barnhart, C., P. Belobaba, and A.R. Odoni, Applications of operations research in the air transport industry. Transportation science, 2003. 37(4): p. 368-391.

44. Kullman, E., Changing the Conversation. The Bridge, 2011. 41(2). 